\title{
Educação física e escolarização na Revista de Educação do Espírito Santo (1934-1937) ${ }^{1}$
}

\author{
Omar Schneider* \\ Marcela Bruschi** \\ Amarílio Ferreira Neto***
}

\begin{abstract}
Resumo: O estudo analisa a Revista de Educação, impresso produzido na cidade de Vitória, entre os anos de 1934 e 1937, para compreender a escolarização da Educação Física no Espírito Santo, durante a gestão do interventor federal João Punaro Bley, e sua proposta de formação de professores aptos a ministrar a disciplina Educação Física nas escolas capixabas.
\end{abstract}

Palavras-chave: Educação Física. Revista de Educação. Escolarização. Espírito Santo.

\section{INTRODUÇÃo}

O estudo analisa a Revista de Educação (do Espírito Santo) (REES), um periódico publicado pelo Serviço de Cooperação e Extensão Cultural do Departamento de Educação em Vitória, entre os anos de 1934 e 1937, para compreender o processo de constituição da Educação Física como disciplina escolar no Espírito Santo e a formação dos professores aptos a ministrá-la.

\footnotetext{
${ }^{1}$ A pesquisa faz parte da investigação História e memória da Educação Física e do esporte no Espírito Santo: autores, atores e instituições (1931-1961), com bolsa Pibic/Ufes e financiamento do CNPq que estão em desenvolvimento no Centro de Educação Física e Desportos da Universidade Federal do Espírito Santo.

"Professor do Centro de Educação Física e Desportos, da Universidade Federal do Espírito Santo (UFES) e membro do Instituto de Pesquisa em Educação e Educação Física (Proteoria) http://proteoria.org. E-mail: omarvix@gmail.com

**Aluna do curso de licenciatura do Centro de Educação Física e Desportos e de Iniciação Científica e membro do Proteoria. E-mail: niba_bruschi@hotmail.com

***Professor do Centro de Educação Física e Desportos, da Universidade Federal do Espírito Santo (UFES) e membro do Proteoria. E-mail: amariliovix@gmail.com.
} 
Desde o início dos anos de 1990, a historiografia da educação tem se debruçado sobre os impressos como objeto de estudo ${ }^{2}$. Os impressos são tomados como material que possibilita desvelar o campo educacional em diferentes dimensões: informa sobre os sistemas escolares e os processos educativos; sobre os modos peculiares de articulação entre teoria e prática e, por conseguinte, sobre a formação do professorado em diferentes períodos; dá a ver as polêmicas, debates e discussões que compõem o processo de constituição do campo educacional. Assim, os impressos são entendidos como material privilegiado para a "[...] apreensão dos modos de funcionamento do campo educacional" (CATANI; BASTOS, 1997, p. 7).

O estudo do mundo dos impressos, principalmente de destinação pedagógica é necessário para a construção de uma história cultural dos saberes pedagógicos, pois é capaz de revelar os "[...] processos de produção, circulação, imposição e apropriação desses saberes [...]" (CARVALHO, 2003). Assim, a análise de um periódico possibilita uma aproximação com as peculiaridades da realidade de sua época, do estudo de seus usos e das práticas de consumo que dele se apoderam, bem como de suas condições de produção e circulação, identificando concepções e aspectos das representações de uma época. Os periódicos especializados, de acordo com Nóvoa (apud CATANI; BASTOS, 1997, p. 6), constituem-se como "[...] o melhor meio para aprender a multiplicidade do campo educativo [...]".

Como os artigos da REES são escritos por autores locais: professores, médicos, inspetores de ensino, esperamos entender quais foram os saberes depositados na REES para a formação do professorado capixaba para o ensino nas escolas primárias e secundárias da Educação Física, entendida como parte fundamental de uma proposta de Pedagogia Moderna, capaz de colocar o Espírito Santo no concerto civilizatório, ao modernizar a sua instrução pública.

A Pedagogia Moderna é produzida e se configura em um processo complexo, de longa duração, de disputas políticas entre

\footnotetext{
${ }^{2}$ Ver Nunes e Carvalho (1993).
} 
grupos e indivíduos singulares que buscam se estabelecer como referência em ambientes de lutas, oposições, acordos e disposições compartilhados sobre modelos pedagógicos e mundos ideais. Mas é possível situar a sua origem com o nascimento da Modernidade e suas revoluções geográficas, econômicas, políticas, sociais, ideológicas, culturais e pedagógicas.

De acordo com Cambi (1999), todo esse complexo processo vem também tocar profundamente sobre o que compreendemos como a educação e a pedagogia que, por sua vez, são radicalmente transformadas tanto no terreno político e religioso como no ético e social e também no técnico. Para compreender o processo de constituição da Pedagogia Moderna e a sua forma escolar, trabalhamos com dois pressupostos: "[...] o de que a forma escolar é produto de práticas de apropriação entendidas como práticas de transformação de matérias sociais específicas; e o de que os modelos pedagógicos são objetos culturais produzidos socialmente e que devem ser analisados em sua materialidade" (CARVALHO, 2003, p. 343, grifos da autora).

\section{A ReVISTA de EduCAÇÃo EM SUA MATERIALIDADE}

AREES teve como o seu primeiro diretor o Dr. Fernando Duarte Rabello, secretário do Interior e Justiça, e seu redator-secretário o professor Claudionor Ribeiro, inspetor-técnico do ensino e chefe do Serviço de Cooperação e Extensão Cultural. Segundo seus idealizadores, a REES foi confeccionada para a divulgação dos métodos contemporâneos de ensino ao professorado capixaba.

$\mathrm{Na}$ investigação, utilizamos os seguintes números do impresso: 1, 2, 3, 6, 7-8 e 9, publicados no ano de 1934. Os números 10-11, 12, $13,14,15-16,17-18-19$ foram lançados no ano de 1935. Os impressos de número 22, 23-24, 25-26-27-28, editados no ano de 1936, e as REES de número 29, 30-31 foram distribuídas no ano de $1937^{3}$.

\footnotetext{
${ }^{3}$ Os números 4, 5, 20, 21, 32, 33 e 34 não foram localizados nos acervos consultados.
} 
Em seus primeiros dois anos, a REES mantinha regularidades na publicação, mas, como é anunciada pela Revista de Educação (1936, p. 69), passa a sofre algumas interrupções, perdendo a periodicidade:

Por motivos de força maior esta Revista deixou de circular nos meses de janeiro, fevereiro, abril, maio e junho do corrente anno. Depois de dois annos de circulação inimterrupta, é esta a primeira falta que cometemos, por motivos imperiosos. A todos que nos tem distinguido com a sua symphatica e generosa acolhida, rogamos a fineza de nos desculpar por este lapso involuntário. A Revista de Educação, circulará doravante com rigorosa pontualidade.

Um dos motivos que poderiam ter levado a essa irregularidade nos anos de 1936 e 1937 pode ter sido causado pela troca de diretor da revista, cargo que passou a ser exercido pelo Dr. Paulino Muller, ficando à frente da Diretoria apenas durante a publicação da REES n. 22, quando Dr. Arnulpho Mattos retorna para a direção do impresso. Lauff (2007) discute que essa mudança de editor pode ter afetado o ritmo de produção do impresso em função da reorganização de alguns setores do periódico.

De acordo com os editores, a promessa era editar a revista mensalmente. Contudo, algumas revistas foram publicadas em conjunto, ou seja, uma mesma revista correspondia a dois ou mais meses. Isso ocorreu na publicação das revistas números 7-8 (outubro e novembro de 1934), 10-11 (janeiro e fevereiro de 1935), 17-18-19 (agosto, setembro e outubro de 1935), 23-24 (julho e agosto de 1936), 25-26-27-28 (setembro, outubro, novembro e dezembro de 1936) e 30-31 (junho e julho de 1937). Essa estratégia editorial pode ter sido adotada como forma de se economizar na publicação, sem perder a regularidade da revista, uma vez que o papel era o item mais caro para a confecção de um impresso nas primeiras quatro décadas do século XX.

No início de sua publicação, o valor do impresso era de $15 \$ 000$ para assinatura anual, $8 \$ 000$ para assinatura mensal e $1 \$ 500$ para assinatura avulsa. Na primeira publicação do ano seguinte, a revista 
estreia com novo valor: $12 \$ 000$ para assinatura mensal, $7 \$ 000$ para assinatura semestral e $1 \$ 000$ para compra avulso. Na revista $n .13$, os preços maiores voltam a vigorar. Contudo, o preço menor prevalece na edição 15-16, mantendo-se até o término da editoração do impresso.

A REES era editada com capa e sumário, apresentando brevemente o que o leitor encontraria em seu interior. As capas eram a marca registrada do impresso e a sua identidade visual. As imagens sempre remetiam à educação, e ora elas mudavam, ora se repetiam. As indicações de número, mês, ano e localidade também variavam em cada capa. Nas matérias, além do título do artigo, seguia-se também o nome do autor e o seu vínculo profissional. A partir da segunda revista, começam-se a apresentar ilustrações no interior do impresso, assim como, na publicação do terceiro número, ocorreu a veiculação de propagandas.

De acordo com Lauff (2007, p. 68), podem-se distinguir três fases da REES: a de crescimento, a de ascensão e a de turbulência. $\mathrm{Na}$ fase de crescimento (de abril de 1934 a abril de 1935), somavamse à revista secções, fotos e anúncios. O período de turbulência caracterizou-se por ascensões e quedas. Foi nesse período que as revistas passaram a ser publicadas em números conjugados, com maior número de páginas e imagens. O período de decadência foi marcado pela queda na produção das edições e seu fim, uma vez que não foi localizado nenhum exemplar que tivesse sido publicado depois de julho de 1937.

Para que a REES fosse produzida, contava com um diretor, um redator-secretário e redatores. Na revista de n. 1, o diretor era o Dr. Fernando Duarte Rabelo (secretário do Interior e Justiça). Do n. 2 ao n. 12, ele foi substituído pelo diretor, o tenente Wolmar Carneiro da Cunha (secretário do Interior e Justiça). Já nas revistas n. 13 e 14, o diretor passou a ser o Dr. Manoel Clodoaldo Linhares (secretário do Interior e Justiça). Nas revistas n. 17-18-19, apresenta-se como diretor o Dr. Carlos Gomes de Sá (secretário do Interior e Justiça). Na revista n. 22, assume como diretor o Dr. Paulino Muller (secretário 
da Educação e Saúde Pública). A partir da publicação dos nº 23-24, 25-26-27-28, 30-31, teve como diretor o Dr. Arnulpho Mattos (secretário da Educação e Saúde Pública).

A análise da REES nos possibilita uma ampla possibilidade de conhecimento sobre a condição da educação no Espírito Santo, informando ainda sobre os seus consumidores idealizados. Ela era direcionada, principalmente, à formação dos professores capixabas, como uma estratégia utilizada pelo Poder Local para fazer circular novas representações sobre o fazer docente. Era percebida como capaz de moldar o professor pelas leituras modelares apresentadas em suas páginas, preenchidas por prescrições realizadas por autores autorizados a tratar dos temas educacionais pelo Poder Central, sintetizado no Espírito Santo pela figura do interventor Federal, Capitão João Punaro Bley.

Sua impressão mensal ficava a cargo do Serviço de Cooperação e Extensão Cultural do Departamento do Ensino Público, sessão destinada a divulgar os métodos e processos contemporâneos de ensino. Desse modo, em sua criação, a REES é tomada como veículo de projeto de modernização do ensino capixaba, de modo a acompanhar o movimento educacional brasileiro, sendo, assim, indicada à formação do professorado. Contudo, ao mesmo tempo em que os impressos nos revelam as características do tempo vivido, ela também toma parte desse processo de criação da atmosfera que permitiu a sua circulação e consumo. Ela foi criada com o objetivo de ser uma forja de representações em um período marcado por disputas sobre quais deveriam ser as características do homem novo alfabetizado e doutrinado para viver a modernidade da Era Vargas. Conforme Chartier (1990, p. 17), as representações "[...] são sempre determinadas pelos interesses dos grupos que as forjam [...], [com isso] tendem a impor autoridade aos outros, por elas menosprezados, a legitimar um projeto reformador ou a justificar, para os próprios indivíduos, suas escolhas e condutas [...]".

Na RESS, a população é representada como formada por pessoas passivas, com perversões sexuais, com horror à responsabilidade, alcoólicos, loucos, doentes e criminosos. Associava- 
se, nas décadas de 1910 e 1929, essa representação do brasileiro à figura do personagem Jeca Tatu, criado por Monteiro Lobato, em 1918, um homem bêbado, preguiçoso e doentio, traços vinculados ao restante do povo "[...] assolado pela doença, decorrente da falta de saneamento, de nutrição e de instrução, mas também fruto do descaso dos governantes" (SCHNEIDER, 2010, p. 16). Era preciso salvar o Brasil dessa degeneração e colocá-lo no nível dos outros países que já se encontravam em um padrão de modernidade elevado. Para os editores, a escola passa, então, a ser observada como solução, lugar capaz de vitalizar e produzir a esperança do progresso para o Brasil.

Esse entusiasmo pela educação, percebido no impresso, teve impulso nas primeiras décadas do século $\mathrm{XX}$, principalmente na década de 1920, pelo movimento conhecido como o entusiasmo pela educaçã $o^{4}$, que se estendeu nas décadas seguintes, principalmente no governo de Getúlio Vargas5, visto que uma de suas principais prioridades foi oferecer educação para toda a população, situação percebida como o grande problema nacional. Assim, a educação, a partir da década de 1930, ganhou destaque nos embates ideológicos que marcavam presença cada vez mais forte na vida política.

Em sua política de reforma, homogeneização e estabilidade, Vargas nomeou interventores para governar os Estados, ficando a cargo do capitão João Punaro Bley o governo do Espírito Santo, importante ator local no movimento revolucionário de 1930.

As reformas empreendidas por Punaro Bley são veiculadas pela REES, o que, segundo os editores, permitia com suas realizações, pôr o Espírito Santo no novo contexto brasileiro. A contribuição de Punaro Bley, para os editores, era essencial para a melhoria da educação do Estado, principalmente do ensino primário, ao adotar a obrigatoriedade da língua portuguesa para as regiões de imigração,

\footnotetext{
${ }^{4}$ Ver Nagle, 1974.

${ }^{5}$ De 1930 a 1934 como Governo Provisório, de 1934 a 1937 como Governo Constitucional e de 1937 a 1945 como Estado Novo.
} 
o ensino da Geografia, da História do Brasil, da instrução moral e cívica e da Educação Física.

A REES deve ser entendida como uma estratégia política do interventor Punaro Bley no campo educacional. Ela marca essa intervenção por meio dos constantes elogios às suas políticas de reforma. Punaro Bley é apontado como o único capaz de resolver os graves problemas educacionais que retardavam o progresso do Estado e, consequentemente, do Brasil. A educação era vista como a única capaz de garantir a felicidade e a superação dos problemas nacionais, pois, como afirmava Ribeiro (1935, p. 16), ao citar Ruy Barbosa, a "[...] educação [seria] a matriz universal da felicidade humana".

\section{ReVISTA de EdducaÇÃo, REPRESENTAÇões da EddCAÇÃo FísıCA E SUA ESCOLARIZAÇÃO}

No estudo, constatou-se grande diversidade de temas no interior da REES, que, trabalhados em conjunto, garantiriam o progresso do Espírito Santo, elevando o ensino e, segundo os editores, "regenerando nossa raça", garantindo a ordem e o progresso, um dos lemas do período. Entre os anos de 1934-1937, observa-se a preocupação em tornar a Educação Física uma realidade na escola capixaba para as crianças em processo de escolarização. $\mathrm{Na}$ REES, é dada grande importância ao corpo biológico, em que a Educação Física permitiria desenvolver o homem de forma harmoniosa, física e mentalmente. Esse movimento fazia parte da implantação da Pedagogia Moderna que procurava reformar a escola com os novos métodos de ensino.

A Educação Física estava associada aos cursos de Educação Sanitária Escolar e aos dispositivos denominados como Serviço Médico Escolar, o Bandeirantismo e o Escotismo, entendidos como práticas essenciais na formação do professorado capixaba, aptos para uma nova prática pedagógica, conceituada como moderna. No interior da REES, são publicados artigos sobre temáticas que o 
Serviço de Cooperação e Extensão Cultural do Departamento de Educação acreditava que deveriam fazer parte de um projeto de educação integral. É importante ressaltar que muitos dos artigos foram escritos por autores relevantes no cenário educacional do Espírito Santo, como Placidino Bastos, Arthur Meireles, Claudionor Ribeiro, recebendo colaboração de autores de outros Estados e, em alguns casos, até a colaboração de autores de outros países. São matérias que trazem como referência as grandes ideias educacionais e educadores festejados, que circulavam naquele momento, como o caso de Pestalozzi, Froebel, Dewey, Fernando de Azevedo, Anísio Teixeira e Lourenço Filho, que são o alicerce da Pedagogia Moderna em seu formato de Escola Nova.

Nessa nova pedagogia, a educação iria centrar-se na criança, que não mais seria passiva; ela seria ativa e o movimento passaria a fazer parte da rotina de suas aprendizagens, que deveriam ser prazerosas, condizentes com os seus interesses e direcionadas às suas vocações.

Como a REES foi criada para divulgação dos modernos métodos contemporâneos de ensino ao professorado capixaba, a Educação Física era apresentada como indispensável no processo de formação dos alunos. Ela era significada nas escolas capixabas, fazendo parte de um projeto sanitário de desenvolvimento físico e intelectual, da disciplina, da moral e do caráter, além da saúde e da higiene. Nesse momento, ao brasileiro eram associados alguns traços negativos que o representavam como melancólico, com perversões sexuais e com horror à responsabilidade, o que dificultava o desenvolvimento da nação. Para superar essas representações, a Educação Física e a Educação Sanitária viam no meio educacional a possibilidade de reverter as visões negativas. Podemos constatar na revista a estreita ligação entre educação e saúde, numa ênfase cada vez maior à Educação Física para o fortalecimento do Brasil. Essa foi uma das justificativas para a criação e manutenção do Departamento de Educação Física ${ }^{6}$.

\footnotetext{
${ }^{6}$ Criado em 26 de junho de 1931 e instituindo um curso de emergência para formação de professores de Educação Física com duração de quatro meses.
} 
Para os editores, um dos objetivos do periódico era educar e modernizar a cultura do Espírito Santo. Assim, na tríade do desenvolvimento moral-físico-intelectual, acreditavam estar a fórmula da potencialização das capacidades humanas, desenvolvidas por meio da Educação Física/ginástica nas escolas capixabas.

Os editores tomavam como exemplo os Estados Unidos, as nações européias e o Japão, por possuírem uma raça forte e bemsucedida por meio da Educação Física. Assim, procuravam, no Brasil, também por meio da Educação Física, alcançar os mesmos patamares obtidos pelos outros países. Desse modo, fazem a seguinte prescrição:

E bem util seria agora, nesta época em que começa a surgir no Brasil um espirito novo, que cada brasileiro tomasse a si a tarefa de retemperar a sua fibra moral; que cada brasileiro buscasse, através da educação fisica, reparar a grande falha do seu traço psicologico que é a falta de vontade e o 'horror a responsabilidade' (FREITAS, 1934, p. 12).

Fernando de Azevedo, um dos grandes intelectuais da educação e também entusiasta da Educação Física no Brasil, é utilizado como referência para dar sentido à Educação Física como matéria no contexto escolar e como prática a ser assimilada pela população espírito-santense. De sua obra é extraída a seguinte prescrição para a Educação Física: "A regeneração fisica, é incontestavelmente um dos maiores fatores do progresso, senão for, talvez, este próprio progresso" (LOUREIRO, 1935, p. 20). Para ele, essa regeneração poderia ser obtida por meio da Educação Física na escola como matéria obrigatória para os alunos.

Diante da necessidade de tornar a Educação Física uma realidade no meio escolar, era preciso que o Estado investisse na formação de professores. Essa necessidade começou a ser suprida com a criação do Departamento de Educação Física em 26 de junho de 1931, realizando o primeiro curso de Educação Física no Brasil, que passou a formar professores no meio civil (instrutores, professores e monitores de Educação Física), visto que antes somente 
existia a formação no meio militar, oferecida pela Escola de Educação Física do Exército no Rio de Janeiro.

O Espírito Santo, de acordo com os artigos publicados pela REES, passou a ser considerado o mais avançado em se tratando de cultura física no Brasil. Com a instituição da Inspetoria de Educação Physica, o curso dessa especialidade assumiu aspectos modernos, adotando o discurso científico e o Método Francês como padrão a ser seguido. O método instituído pelo Decreto no 1.366/31, para orientar a prática da Educação Física nos estabelecimentos de ensino, foi o Método Francês de ginástica ${ }^{7}$.

A formação estava representada por um triângulo que tinha como foco uma educação integral: físico, moral e intelectual. Chegouse à conclusão de que, só pelo bom funcionamento de todos os órgãos, pelo equilíbrio físico e mental é que se poderia conceber uma educação capaz de proporcionar a felicidade humana, sendo esse o preponderante papel da Educação Física. Assim, um método de educação deveria satisfazer essas exigências e o Método Francês correspondia perfeitamente às descobertas científicas mais recentes, satisfazendo as necessidades sociais por ter como fim o aperfeiçoamento da raça.

Acreditava-se que, para o pleno desenvolvimento do Brasil, a Educação Física deveria ser associada a outros saberes, principalmente relacionados com a saúde. Quanto a isso, o governador João Punaro Bley não poupou esforços. Uma de suas primeiras medidas foi a criação do Serviço de Inspeção Médica e Educação Sanitária Escolar pelo Decreto no 4.012, em 22 de agosto de 1933. O ensino da Educação Sanitária começaria na escola primária, onde os alunos deveriam sair com as primeiras noções sobre as doenças contagiosas ${ }^{8}$, o que os tornariam conhecedores dos meios de adquirir, transmitir e eliminar os agravos à saúde. A

\footnotetext{
${ }^{7} \mathrm{~A}$ escolha do Método Francês foi influenciada pelos fundadores do Departamento (tenentes Carlos Marciano de Medeiros, Horácio Cândido Gonçalves e Wolmar Carneiro da Cunha), vindos do Centro Militar de Educação Física do Exército.

${ }^{8}$ Chama a atenção na REES a comparação que se faz entre o Brasil e os outros países em relação aos investimentos para o combate às doenças.
} 
Educação Sanitária no meio escolar ensinaria que a prática da Educação Física poderia manter o corpo sempre forte e saudável, livre de qualquer doença.

O Movimento do Escotismo e do Bandeirantismo são bastante enfatizados nas REES como prática social capaz de desenvolver o caráter e o corpo. $\mathrm{O}$ Escotismo já era adotado em algumas escolas brasileiras como complemento para o que denominavam de educação integral. Sua proposta é o desenvolvimento do jovem, favorecendo a formação de valores morais, físicos e intelectuais, um exemplo de responsabilidade, respeito e de disciplina.

Esse movimento ganhou força no Brasil e passou a ser percebido como importante para a formação e propagação do sentimento de nacionalidade. Nesse momento, o Escotismo recebeu grande incentivo, juntamente com o Bandeirantismo, que tinha a mesma finalidade e organização do Escotismo, só que era direcionado às moças.

O bandeirantismo forma o carater das moças.
Desenvolve-lhes o espirito de familia e de civismo.
Faz, de cada mulher, um modelo de paciência, de
bondade, de nobres aptidões e útil a si mesma e á
coletividade. Forma a mulher perfeita, capaz,
dignificadora do lar, por meio de praticas morais,
trabalhos úteis, excursões, jogos e exercícios.
Habilitaria a mulher para as ocupações domesticas
e para ter confiança nela mesma (REVISTA DE
EDUCAÇÃO, 1934, p. 36).

A REES também tinha como projeto o intercâmbio cultural, o fomento e a aproximação entre os países americanos, o que deveria ser mantido pelo Serviço de Cooperação e Extensão Cultural. Esse intercâmbio tinha sua ação voltada para um maior desenvolvimento comercial, um intercurso de amizade e maior aproximação entre as Repúblicas Americanas.

Dentre os principais objetivos dessa união pan-americana, estava a troca de informações entre os professores envolvidos nas discussões em torno das tendências pedagógicas. Os textos 
publicados na revista tinham como objetivo a formação contínua dos professores, uma vez que, lendo a revista, poderiam estar sempre atualizados com os temas pedagógicos, com as discussões e com as mudanças nas políticas do Estado para o campo educacional.

Nos Estados Unidos, de acordo com os artigos publicados pela REES, dava-se grande ênfase à Educação Física para a formação de sua população. Assim, a Educação Física americana era vista como um exemplo de perfeição a ser seguido pelos demais países. Em seus discursos, ressalta-se o grande amor à Educação Física, pois é por meio dela que os homens passariam a ser perfeitos, desenvolvendo harmoniosamente suas aptidões intelectuais, morais e físicas. Aos leitores é oferecido um conselho:

Moços do Espirito Santo: Não vos descuideis dos exercícios fisicos. Fundai o vosso clube da saude. E que a vossa vitoria de dias atrás seja o vosso maior estimulo para a realização de educação física. Porque, senhores, a Educação para ser completa e corresponder aos seus objetivos, para ser harmonica e corresponder aos seu ideal de equilibrio e de valorização, necessita forçosamente da cultura destes dois fatores: Corpo e Espírito (MEIRELES, 1934, p. 6).

Dentro desse novo contexto, foram abordadas novas perspectivas acerca da formação dos professores para trabalhar com a Educação Física. Nessa proposta de formação, o discurso da saúde, da higiene e da ginástica eram imprescindíveis, uma vez que o Método Francês de exercitação corporal, conhecido como Regulamento $\mathrm{n}^{\circ}$ 7, oficial para o uso nas escolas, possuía uma matriz biológica, em que o movimento humano era entendido com base em uma análise anatomomecânico e pela sua dimensão biológica. A adoção do Método Francês estava direcionada para o aprimoramento da saúde, o fortalecimento da raça e a manutenção da ordem.

A REES se constitui em um indício do movimento que torna a Educação Física uma disciplina no currículo escolar e a Pedagogia Moderna uma realidade no Espírito Santo, ao adotar o mote da educação integral (moral-físico-intelectual). Também é um vestígio 


\section{ArtigosOriginais}

das estratégias empregadas pelo Estado para a organização do Brasil, das reformas de Punaro Bley, de um projeto de formação para os professores e da proposta de escolarização da Educação Física em terras capixabas.

\section{Considerações finaIS}

A REES é um objeto que guarda marcas culturais de sua criação, das prescrições sobre o campo educativo e dos destinatários visados. Ela permite perceber a diversidade de temas que são tratados como imprescindíveis ao desenvolvimento do Espírito Santo na década de 1930.

As prescrições que circularam no impresso que trataram das temáticas da saúde e da ginástica são entendidas como conteúdos potencializadores dos discursos que buscaram significar a presença da Educação Física no ambiente escolar, tanto pelo seu conteúdo disciplinador (percebido como necessário pelos atores que organizaram o impresso), quanto pelas mudanças que, uma educação que tem como base tais temas, poderiam demonstrar em relação à modernidade pedagógica alcançada pelo Estado em relação ao restante do país.

O impresso foi editado conforme as diretrizes do movimento escolanovista e foi direcionado principalmente ao professorado capixaba para introduzi-lo nos métodos modernos e contemporâneos de educação. A REES apresenta, em suas páginas, as medidas adotadas pelo governo de Punaro Bley para incutir no capixaba a mentalidade do ideal nacional de Getúlio Vargas. Faz perceber que ao corpo biológico era dada grande ênfase, pois seu desenvolvimento e manutenção seria necessário para atender às novas exigências da sociedade que se industrializava.

Nessa nova fase pela qual passava a sociedade, intensificamse as preocupações acerca da melhor forma de ensino, da melhor 
escola e, consequentemente, da necessária formação para os professores, priorizando também uma educação pública, gratuita e universal.

Segundo Tomazetti (2003, p. 97),

Se a sociedade estava mudando, era preciso que a escola preparasse o novo homem, o homem moderno, para que ele pudesse viver bem na nova sociedade que deveria ser, acima de tudo, uma sociedade democrática. É fácil demonstrar como todos os pressupostos em que a escola se baseava foram alterados pela nova ordem de coisas e pelo novo espírito de nossa civilização.

Diante dessa necessidade, profissionais deveriam estar mais bem capacitados em oferecer um ensino eficiente. Assim, viu-se o Espírito Santo mergulhado em uma nova investida no plano educacional, atualizando seus profissionais com a criação de vários cursos, construção de novas escolas e preocupação no oferecimento da Educação Física a todos os educandos, mesmo nos municípios mais distantes da capital, Vitória. Coube a REES a divulgação dos modernos métodos educacionais direcionados principalmente à formação dos professores e à divulgação do novo patamar educacional alcançado pelo Espírito Santo. 


Physical Education schooling in the Revista de
Educação of the State of Espírito Santo (1934 -
1937)
Abstract: The paper analyzes the Revista de
Educação, prospectus produced in the city Vitória, in
the years 1934 and 1937 , aiming at comprehending
the schooling of the Physical Education in the state of
Espírito Santo during the management of the federal
interventor named João Punaro Bley, and his proposal
to form teachers able to teach the school subject
Physical Education in the Espírito Santo schools.
Keywords: Physical Education. Revista de Educação.
Schooling. Espírito Santo.

Educación Física y escolarización en la Revista
de Educação de Espírito Santo (1934-1937)
Resumen: El estudio analiza la Revista de Educação,
impreso producido en la ciudad de Vitória, mientras
los años de 1934 y 1937, para comprender la
escolarización de la Educación Física en el Espírito
Santo, durante la gestión del interventor federal João
Punaro Bley, y suya propuesta de formación de
profesores aptos a ministrar la disciplina Educación
Física en las escuelas de Espírito Santo.
Palabras-clave: Educación Física. Revista de
Educação. Escolarización. Espírito Santo

\section{REFERÊNCIAS}

CAMBI, Franco. História da pedagogia. São Paulo: Unesp, 1999.

CARVALHO, Marta Maria Chagas de. A escola e a República e outros ensaios. São Paulo: Editora Universitária São Francisco, 2003.

CATANI, Denice Bárbara; BASTOS, Maria Helena Câmara (Org.). Educação em revista: a impressa periódica e a história da educação. São Paulo: Escrituras, 1997.

CHARTIER, Roger. A história cultural: entre práticas e representações. Lisboa: Difel, 1990.

FREITAS, Napoleão de. A educação física como fonte de moral. Revista de Educação, Victoria, v. 1, n. 2, p. 12, maio 1934. 
LAUFF, Rafaelle Flaiman. Útil e agradável: a revista de educação (1934-1937) remodelização das práticas de ensino e divulgação da política reformista educacional do governo de João Punaro Bley no Espírito Santo, 2007. Dissertação (Mestrado em Educação: História, Política, Sociedade) - Pontifícia Universidade Católica de São Paulo, São Paulo, 2007.

LOUREIRO, Sylvia Carlos. Educação physica: seus effeitos physiologicos. Revista de Educação, Victoria, v. 1, n. 10-11, p. 20, jan./fev. 1935.

MEIRELES, Arthur. O Serviço Medico Escolar em face da educação e da saúde. Revista de Educação, Vitória, v. 1, n. 2, p. 6, maio 1934.

NAGLE, Jorge. Educação e sociedade na Primeira República. São Paulo: EPU; Rio de Janeiro: Fundação Nacional de Material Escolar, 1974.

NÓVOA, Antônio. A imprensa de educação e ensino. In: CATANI, Denice Bárbara; BASTOS, Maria Helena Câmara (Org.). Educação em revista: a impressa periódica e a história da educação. São Paulo: Escrituras, 1997. p. 11-31.

NUNES, Clarice; CARVALHO, Marta Maria Chagas de. Historiografia da educação e fontes. Cadernos da ANPED, Belo Horizonte, n. 5, p. 7-64, set. 1993.

REVISTA de educação. Revista de Educação. Vitória, ano 3, n. 23-24, p. 69, jul./ ago. 1936.

RIBEIRO, Orlandina. Como o methodo francês satisfaz as exigências da educação physica. Revista de Educação, Victoria, v. 2, n. 12, p. 16, mar. 1935.

SCHNEIDER, Omar. Educação physica: a arqueologia de um impresso. Vitória: Edufes, 2010.

TOMAZETTI, Elisete M. Filosofia da educação: um estudo sobre a história da disciplina no Brasil. ljuí: Ed. Unijuí, 2003.

VITORIA e o Movimento Bandeirante. Revista de Educação, Vitória, v. 1, n. 2, p. 36, maio 1934.

Endereço para correspondência:

PROTEORIA

Caixa Postal 9905

AGF UNIVERSITÁRIA

Rua Arthur Czartoryski 455 Loja 1

CEP.: 29060-974 
